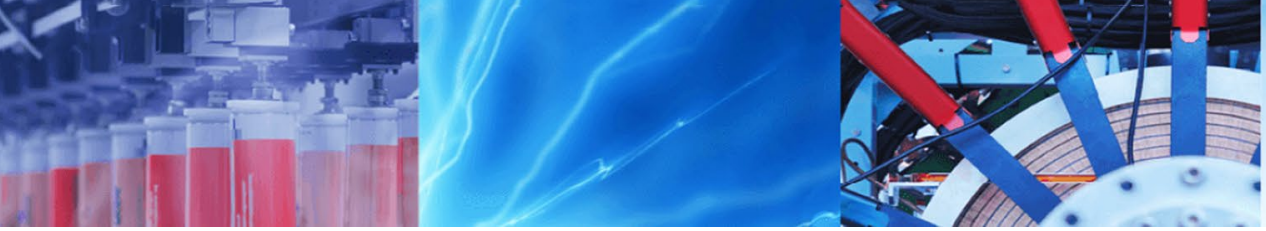

Research Article

\title{
Effects of PGPR on growth and photosynthetic pigment of Trigonella foenum-graceum and Brassica juncea in PAH-contaminated soil
}

\author{
Ruchi Urana' ${ }^{1}$. Namita Singh ${ }^{2} \cdot$ Praveen Sharma $^{1}$
}

(c) Springer Nature Switzerland AG 2019

\begin{abstract}
This study aimed to evaluate the impact of plant growth-promoting rhizobacteria (PGPR) on growth and photosynthetic pigment of two plant species, Trigonella foenum-graceum (methi) and Brassica juncea (mustard), grown in PAH-contaminated saline soil. Pot experiments were conducted for 30 days with the selected plant species in saline soil artificially supplemented with phenanthrene $(5,50,200$ and $400 \mathrm{mg} / \mathrm{kg})$ and naphthalene $(5,50,200$ and $400 \mathrm{mg} / \mathrm{kg})$. After 30 days of growth, both plants were evaluated for morphological changes including root and shoot length and biomass of mucilaginous material using three-way ANOVA and Duncan's new multiple range test $(P \leq 0.05)$. Experimental results clearly indicated that PGPR had a positive impact on overall growth as compared to the non-PGPR-treated plant species.
\end{abstract}

Keywords Winter crops · PAH compounds · Chlorophyll content · Growth parameters

\section{Introduction}

Petroleum is an integral part of industrialized society. Polycyclic aromatic hydrocarbons (PAH) are the by-product of incomplete combustion of petroleum products [10]. The Department of Environment (1987) and Environment Agency (2002) have formulated guidelines regarding toxic levels of PAHs based on land use [9, 14]. There are various sources from which PAHs accumulate in the soil, such as combustion of petroleum products, burning of coal for domestic purposes and leakage from gas pipelines. The effect of PAHs on plants was recently documented [9], showing that PAHs lead to decreased photosynthetic activity of enzymes which are antioxidant in nature. PAHs also affect lipid peroxidation, damage DNA and reduce plant growth [2]. The removal of PAH compounds from the soil is difficult due to their resistant nature, with the exception of naphthalene. PAH compounds having a structure of 3-4 benzene rings are insoluble in water and less volatile in nature; thus they show less degradation in soil $[5,18]$.
PAH contamination of soil leads to changes in the various chemical and physical properties of the soil and microorganisms [12]. Measurable changes in soil microbes affect biochemical processes in the soil, such as the mobility of elements that exist in trace amounts [21]. A change in the bioavailability of trace elements leads to inhibited plant growth and reduced chlorophyll content [22]. Addressing problems related to PAH compounds in our environment has become a global challenge [30]. Phytoremediation is a developing technology which is used to clean oil-contaminated sites, water bodies and soil with the help of flora [8]. Various plant species have shown promise for phytoremediation of PAH pollutants [11]. There are two major techniques involved in phytoremediation of contaminated soils. The first involves dissipation of pollutants from the soil from inside the plant, which is known as phytoextraction. The second is rhizoremediation, in which plants degrade pollutants in the soil with the help of exudates secreted by the plants and the microbial community present in the rhizospheric zone $[3,12]$. The ultimate goal of

\footnotetext{
$\triangle$ Praveen Sharma, ps.enbt@gmail.com | 'Department of Environmental Science and Engineering, Guru Jambheshwar University of Science and Technology, Hisar, Haryana 125001, India. ${ }^{2}$ Department of Bio and Nano Technology, Guru Jambheshwar University of Science and Technology, Hisar, Haryana 125001, India.
} 
the use of vegetation is to remove PAH compounds from the contaminated soil. This can be done through the use of plant-microbe interactions in PAH-contaminated soil, which improve the chemical properties and increase the microbial population in the rhizospheric zone [5]. This technology is cost-effective and environmentally friendly, and is generally socially acceptable [6]. It has many benefits, including reduced soil erosion and water run-off, fortification of plant roots and enhanced aesthetic value [8]. To achieve a reduction in PAH compounds in soil, a stable vegetation cover native to the area is needed. The plants should have maximum root area, should be tolerant of stress conditions and should have good seed germination in contaminated soil $[5,27]$. The plant species that are used are endemic and tolerant of the soil conditions. In the present study, we have taken Trigonella foenum-graceum and Brassica juncea plant species, which are stress-tolerant and produce a large amount of exudates that are helpful in increasing the microbial load in the rhizospheric zone and seed germination in contaminated soil [4]. To enhance degradation of PAH compounds in the soil, we inoculated plant growth-promoting rhizobacteria (PGPR), consisting of Azotobacter and Pseudomonas, with two PAH compounds, naphthalene and phenanthrene, because these compounds are present in the environment and easily accumulate in the soil. The aim of the study is to evaluate the effect of PGPR on the growth parameters and chlorophyll content of Trigonella foenum-graceum and Brassica juncea.

\section{Material and methodology}

In this experiment, Trigonella foenum-graceum (Pusa Early Bunching, PEB) and Brassica juncea (Raya RH-749) of the Fabaceae family were used, and plant seeds of this variety were procured from the CCS Haryana Agriculture University, Hisar (Haryana).

\subsection{Plant and soil preparation}

The seed surfaces were sterilized with mercuric chloride for $1 \mathrm{~min}$ and then rinsed with tap water three times before they were used for sowing. Seeds were sown in pots containing sandy loamy soil which was contaminated with naphthalene and phenanthrene at different concentrations:

1. Naphthalene: $5,50,200$ and $400 \mathrm{mg} / \mathrm{kg}$.

2. Phenanthrene: $5,50,200$ and $400 \mathrm{mg} / \mathrm{kg}$.

In the experiment, we used 5-kg pots and soil taken from Guru Jambheshwar University $\left(29^{\circ} 9^{\prime} 12.6072^{\prime \prime} \mathrm{N}\right.$ and $\left.75^{\circ} 42^{\prime} 42.0732^{\prime \prime} \mathrm{E}\right)$, Hisar (Haryana, India). The experiment was performed in triplicate for each treatment (96 pots) of phenanthrene and naphthalene, and a control without any treatment was also maintained. PGPR (Azotobacter and Pseudomonas) were also added to 48 of the pots with phenanthrene and naphthalene. The PGPR was collected from the Microbiological Lab of Chaudhary Charan Singh Haryana Agricultural University, Hisar, Haryana, 125001. In each pot, $25 \mathrm{ml}$ of PGPR was added along with $0.5 \mathrm{~g}$ of seeds for each plant species (Trigonella foenum-graceum and Brassica juncea); tap water was added to maintain $60 \%$ moisture content.

\subsection{Analysis of root length and shoot height}

After 1 month of plant growth, plants were removed from the different pots and weighed to determine their "fresh weight". Then the height of shoots and length of roots and primary roots were measured with a measuring tape. All plants were then dried in an oven at $94^{\circ} \mathrm{C}$ for $52 \mathrm{~h}$, after which they were allowed to cool at room temperature, and were subsequently weighed to determine their "dry weight". The water content and standing biomass were then calculated as shown below:

Water content $=$ Fresh weight-Dry weight

Standing Biomass $=$ Dry weight $/$ plot area.

\subsection{Photosynthetic pigment analysis}

Fresh leaves $(0.5 \mathrm{~g})$ were put in $70 \%$ acetone and homogenized in $50 \mathrm{ml}$ of acetone. The homogenate was centrifuged at $12,180 \times g(R C F)$ in a REMI PR-24 centrifuge for $10 \mathrm{~min}$ and then filtered. The supernatant was removed and placed in graduated cylinders. Leaf extract was transferred to a $1-\mathrm{cm}$ cuvette, and absorbance readings were taken using a UV-Vis spectrophotometer (Cary 300) at 663$\mathrm{nm}$ and $645-\mathrm{nm}$ wavelengths to determine the concentration of photosynthetic pigment.

$$
\begin{aligned}
& \text { Chl - } \mathrm{a}=12.7 \mathrm{DX663}-2.69 \mathrm{DX} 645 \times \mathrm{V} / 1000 \mathrm{~W}\left(\mathrm{ug} \mathrm{g}^{-1} \mathrm{~F} \mathrm{Wt}\right) \\
& \mathrm{Chl}-\mathrm{b}=22.9 \mathrm{DX} 645-4.68 \mathrm{DX} 663 \times \mathrm{V} / 1000 \mathrm{~W}\left(\mathrm{ug} \mathrm{g}^{-1} \mathrm{~F} \mathrm{Wt}\right)
\end{aligned}
$$

Carotenoids $=\frac{(A 480+0.114 \times A 663-0.638 \times A 645) \times A V \times 1000}{112.5 \times \text { weight of sample }}$

$\mathrm{DX}=$ the absorbance of the extract at the $x \mathrm{~nm} ; V=$ total volume of the chlorophyll solution $(\mathrm{ml}) ; W=$ weight of the tissue extract (g)

\subsection{Measurement of microbial load}

One gram of soil was dissolved in $100 \mathrm{ml}$ of distilled water, and the solution was mixed thoroughly by vortexing. In the next step, $1 \mathrm{ml}$ of the diluted bacterial sample 
was taken from the stock solution. The sample was then poured into a test tube and diluted to a volume of $10 \mathrm{ml}$. The procedure was repeated until dilutions of $10^{-7}$ were obtained. Next, nutrient agar plates were prepared, and $0.3 \mathrm{ml}$ of suspension solution from each dilution was spread over the plates. The plates were then incubated at $37^{\circ} \mathrm{C}$ for $24 \mathrm{~h}$, after which bacterial colonies were counted.

Counting colony forming unit

$$
=\frac{\text { Number of CFU }}{\text { Volume plated }(\mathrm{ml}) \times \text { Total dilution used }}
$$

\subsection{Statistical analyses}

The effects of treatments were evaluated by ANOVA, and means were compared using Duncan's test $(P<0.05)$.

\section{Results and discussion}

Phenanthrene and naphthalene were used in this experiment. Phenanthrene had adverse effects on both Trigonella foenum-graceum and Brassica juncea as compared to naphthalene. The experiment was conducted over a period of 1 month, during which maturity was achieved by both plant species. Sampling was conducted in December 2016, and growth and chlorophyll parameters were analysed using Duncan's new multiple range test method at the $5 \%$ level. Values of $P \leq 0.05$ were considered statistically significant. In order to understand the tolerance effect of both plant species and the effect of PGPR in the contaminated soil mixed with $\mathrm{PAHs}$ at different concentrations, physiological changes including growth parameters and chlorophyll content were taken into consideration.

\subsection{Growth parameters}

Figures 1, 2 and 3 display the total root length, shoot length and plant biomass. Phenanthrene and naphthalene affected plant growth in different ways and at different concentrations of the pollutants in the soil. The addition of phenanthrene at different concentrations in soil $(5,50,200$ and $400 \mathrm{mg} / \mathrm{kg}$ ) caused a measurable change (decrease) in shoot, root and total biomass in the two plant species, as compared to those of control plants (no treatment). Root length and biomass were affected to some extent (i.e. $13.53 \mathrm{~cm}, 0.01186 \mathrm{~g} / \mathrm{cm}^{2}$ at $50 \mathrm{mg} / \mathrm{kg} ; 12.13 \mathrm{~cm}, 0.01176 \mathrm{~g} /$ $\mathrm{cm}^{2}$ at $200 \mathrm{mg} / \mathrm{kg} ; 11.50 \mathrm{~cm}, 0.0114 \mathrm{~g} / \mathrm{cm}^{2}$ at $400 \mathrm{mg} / \mathrm{kg}$ ) for Trigonella foenum-graceum, and to a greater extent $\left(32.50 \mathrm{~cm}, 0.0133 \mathrm{~g} / \mathrm{cm}^{2}\right.$ at $50 \mathrm{mg} / \mathrm{kg} ; 31.73 \mathrm{~cm}, 0.0129 \mathrm{~g} /$ $\mathrm{cm}^{2}$ at $200 \mathrm{mg} / \mathrm{kg} ; 30.40 \mathrm{~cm}, 0.0126 \mathrm{~g} / \mathrm{cm}^{2}$ at $400 \mathrm{mg} / \mathrm{kg}$ ) for Brassica juncea (excluding at $5 \mathrm{mg} / \mathrm{kg}$, which showed exclusive reduction i.e. $0.0087 \mathrm{~g} / \mathrm{cm}^{2}, 9.53 \mathrm{~cm}$ for Trigonella foenum-graceum and $29.50 \mathrm{~cm}, 0.0087 \mathrm{~g} / \mathrm{cm}^{2}$ for Brassica juncea). Shoot length decreased with doses of $50 \mathrm{mg} / \mathrm{kg}$ $(58.43 \mathrm{~cm}), 200 \mathrm{mg} / \mathrm{kg}(54.63 \mathrm{~cm})$ and $400 \mathrm{mg} / \mathrm{kg}(52.63 \mathrm{~cm})$ in Brassica juncea, whereas in Trigonella foenum-graceum,

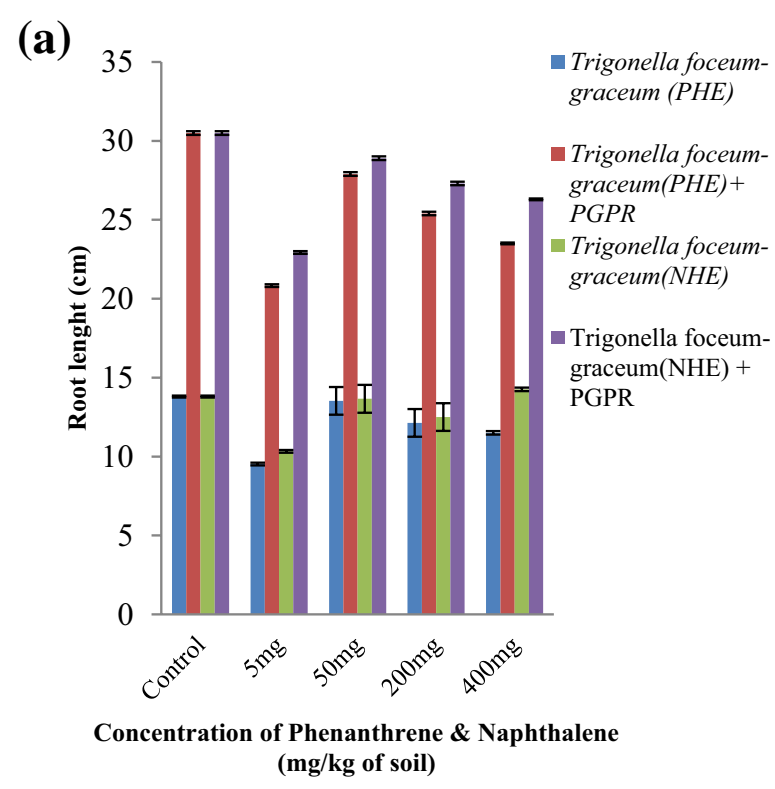

Fig. 1 a Effects of naphthalene (NHE) and phenanthrene (PHE) on root length of Trigonella foenum-graceum with or without PGPR. b Effects of naphthalene (NHE) and phenanthrene (PHE) on biomass

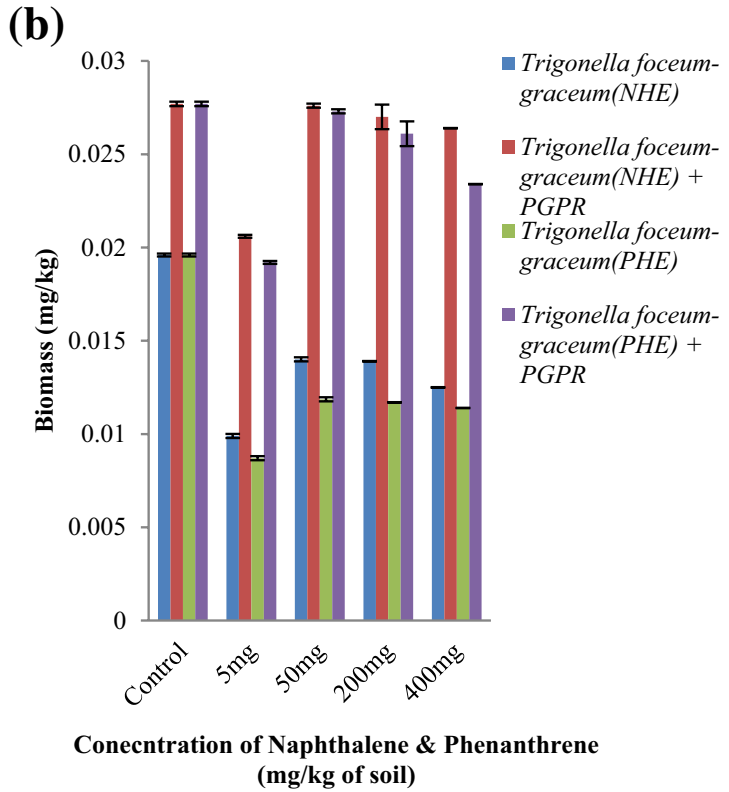

of Trigonella foenum-graceum with or without PGPR. Data for each parameter were analysed separately using three-way ANOVA followed by Duncan's new multiple range test 


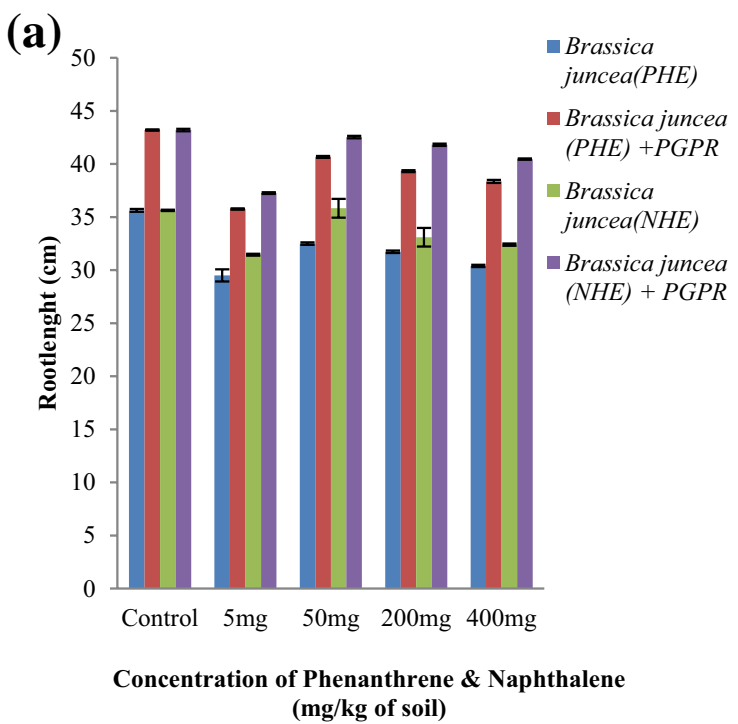

Fig. 2 a Effects of naphthalene (NHE) and phenanthrene (PHE) on root length of Brassica juncea with or without PGPR. $\mathbf{b}$ Effects of naphthalene (NHE) and phenanthrene (PHE) on biomass of Brassica

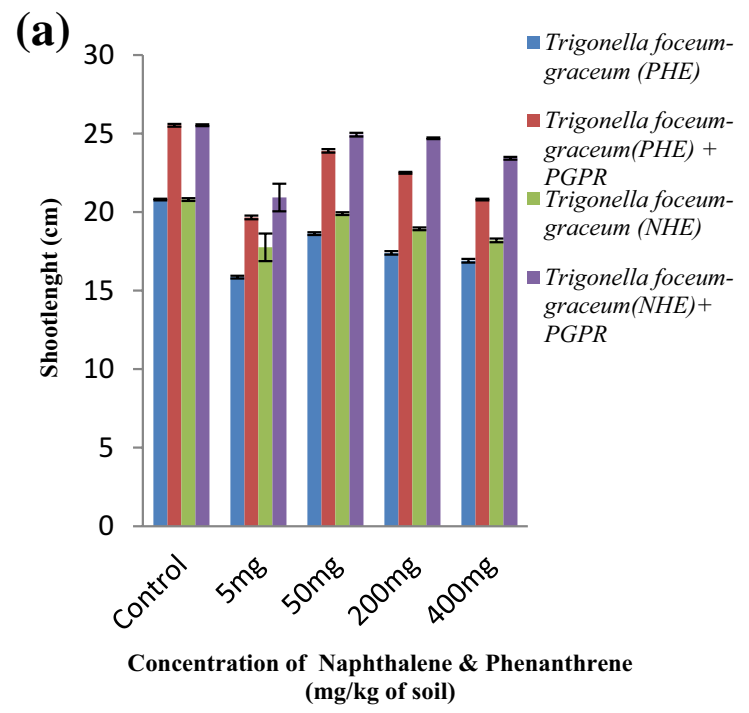

Fig. 3 a Effects of naphthalene (NHE) and phenanthrene (PHE) on shoot length of Trigonella foenum-graceum with or without PGPR. b Effects of naphthalene (NHE) and phenanthrene (PHE) on shoot

the values were $18.63 \mathrm{~cm}, 17.40 \mathrm{~cm}$ and $16.90 \mathrm{~cm}$ for doses of 50,200 and $400 \mathrm{mg} / \mathrm{kg}$, respectively. Toxicity symptoms such as chlorosis and stunted growth were observed at the $5-\mathrm{mg} / \mathrm{kg}$ dose 10 days after applying phenanthrene, whereas in the case of naphthalene, visually evident toxic effects and reduced growth were less pronounced at different concentrations for both Trigonella foenum-graceum and Brassica juncea. The addition of naphthalene had a marked effect on the growth of Brassica juncea but not Trigonella

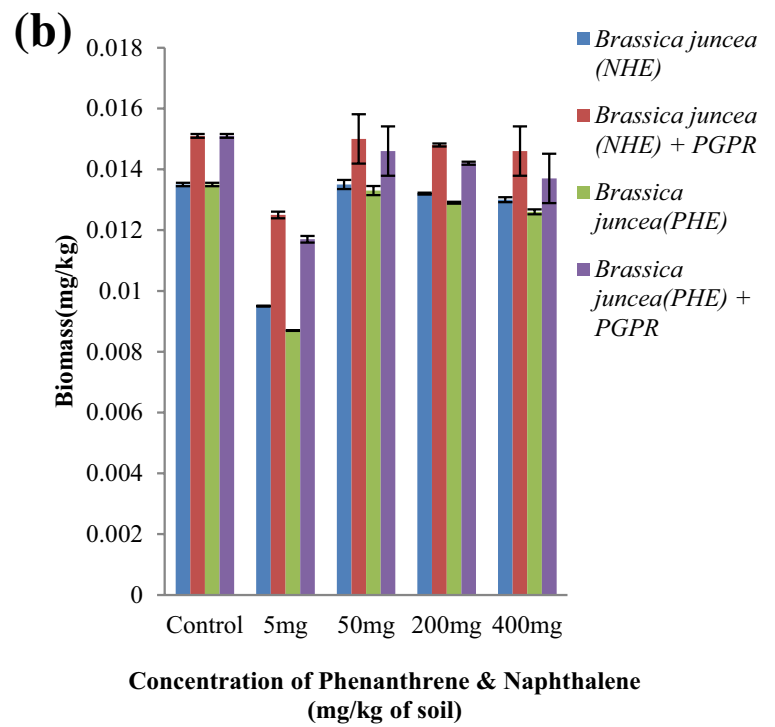

juncea with or without PGPR. Data for each parameter were analysed separately using three-way ANOVA followed by Duncan's new multiple range test

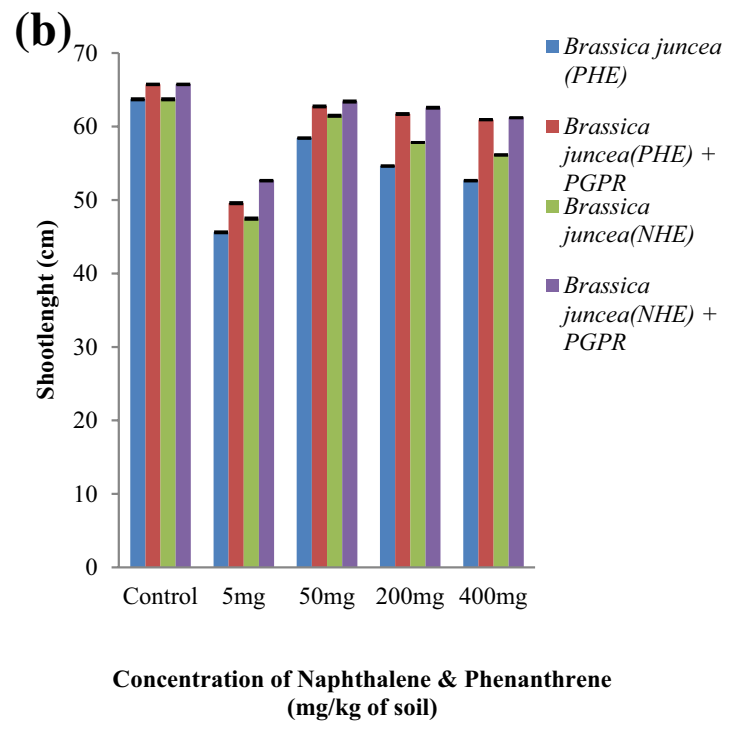

length of Brassica juncea with or without PGPR. Data for each parameter were analysed separately using three-way ANOVA followed by Duncan's new multiple range test

foenum-graceum; nevertheless, the decreased growth was less pronounced than that for treatment with phenanthrene. The study revealed that the effects on the growth of both species were markedly affected by phenanthrene as compared to naphthalene, whereas Trigonella foenumgraceum showed resistivity towards both compounds. Degradation of PAHs in Triticum aestivum has been reported; the observed results, based on the degradation ratios of PAHs in different soil (i.e. planted and unplanted), confirm 
the impact of Triticum aestivum. PAH content was lower in the soil in which different species were planted. The loss of the PAH is due to biotransformation, biodegradation and uptake by plants from the soil [19, 20, 23, 28]. Many research studies have reported that the accumulation of $\mathrm{PAHs}$ in plants is negligible [16, 32]. Loss of phenanthrene is due predominantly to plant-promoted biodegradation. The enhanced dissipation of phenanthrene in the planted soil is due to the microorganisms present in the rhizospheric zone. Soil containing plant litter and root exudates is more favourable for transformation of the microbes, providing substrates for co-metabolic dissipation and enhancing the bioavailability of the contaminants [16]. To enhance the growth rate of the plants, PGPR was added to the soil, which led to $75 \%$ enhancement of biomass in Trigonella foenum-graceum, while shoot and root length were increased by $68 \%$. Similarly, in the case of Brassica juncea, biomass increased by $65 \%$, whereas the shoot length and root length were increased by $80 \%$.

\subsection{Effect of PGPR}

PGPR were used to enhance plant growth under conditions of stress and contamination. PGPR showed a tremendous effect on both growth and chlorophyll content of plants. The growth parameters of PGPR-treated plants differed significantly $(P \leq 0.05)$ from those of nonPGPR-treated plants, as assessed by three-way ANOVA and Duncan's new multiple range test. In Trigonella foenumgraceum, 75\% increased biomass was observed as compared to non-PGPR plants, whereas shoot and root length were increased by $68 \%$. Similarly, in the case of Brassica juncea, biomass increased by $65 \%$, while shoot and root length increased by approximately $80 \%$. To estimate the effect of PGPR on microbial growth, the colony counting method was used. The bacterial colonies were observed to increase with increased concentrations of phenanthrene and naphthalene, as shown in Table 1. Among the four concentrations, maximum growth of bacterial colonies $\left(9.89 \times 10^{10}\right)$ was observed at $400 \mathrm{mg} / \mathrm{kg}$.

The study showed that PGPR counterbalanced the deleterious effect of phenanthrene and naphthalene by enhancing microbial growth in the soil, leading to enhanced stress tolerance in these plants as compared to the non-PGPR plants.

Table 1 CFU values obtained by ANOVA (Duncan's new multiple range test) for Trigonella foenum-graceum and Brassica juncea

\begin{tabular}{|c|c|c|}
\hline \multirow[t]{2}{*}{ Treatment (mg) } & \multicolumn{2}{|c|}{ Bacterial colonies in $1 \mathrm{~g}$ of soil planted with Trigonella foenum-graceum } \\
\hline & Without PGPR & PGPR \\
\hline \multicolumn{3}{|l|}{ Phenanthrene } \\
\hline 5 & $3.56 \times 10^{10}$ & $4.47 \times 10^{10}$ \\
\hline 50 & $4.98 \times 10^{10}$ & $6.31 \times 10^{10}$ \\
\hline 200 & $7.24 \times 10^{10}$ & $9.76 \times 10^{10}$ \\
\hline 400 & $8.76 \times 10^{10}$ & $9.89 \times 10^{10}$ \\
\hline \multicolumn{3}{|l|}{ Naphthalene } \\
\hline 5 & $2.84 \times 10^{10}$ & $3.31 \times 10^{10}$ \\
\hline 50 & $3.86 \times 10^{10}$ & $4.17 \times 10^{10}$ \\
\hline 200 & $5.20 \times 10^{10}$ & $5.43 \times 10^{10}$ \\
\hline 400 & $6.01 \times 10^{10}$ & $6.75 \times 10^{10}$ \\
\hline \multirow[t]{2}{*}{ Treatment (mg) } & \multicolumn{2}{|c|}{ Bacterial colonies in $1 \mathrm{~g}$ of soil planted with Brassica juncea } \\
\hline & Without PGPR & PGPR \\
\hline \multicolumn{3}{|l|}{ Phenanthrene } \\
\hline 5 & $2.36 \times 10^{10}$ & $3.27 \times 10^{10}$ \\
\hline 50 & $3.62 \times 10^{10}$ & $4.11 \times 10^{10}$ \\
\hline 200 & $5.24 \times 10^{10}$ & $6.26 \times 10^{10}$ \\
\hline 400 & $7.46 \times 10^{10}$ & $8.19 \times 10^{10}$ \\
\hline \multicolumn{3}{|l|}{ Naphthalene } \\
\hline 5 & $1.34 \times 10^{10}$ & $2.01 \times 10^{10}$ \\
\hline 50 & $2.16 \times 10^{10}$ & $3.27 \times 10^{10}$ \\
\hline 200 & $3.40 \times 10^{10}$ & $4.13 \times 10^{10}$ \\
\hline 400 & $5.51 \times 10^{10}$ & $5.93 \times 10^{10}$ \\
\hline
\end{tabular}




\subsection{Chlorophyll and carotenoid content}

The effect of phenanthrene and naphthalene on the chlorophyll parameters is given in Table 2 . From the results, it is evident that phenanthrene and naphthalene had different effects on the two plant species Trigonella foenumgraceum and Brassica juncea. Although both treatments had a negative effect on all the measured chlorophyll parameters, the effects of phenanthrene were greater than those of naphthalene. The highest inhibition with $5-\mathrm{mg} /$ $\mathrm{kg}$ treatment $\left(1.365 \pm 0.0015 \mathrm{mg} / \mathrm{m}^{-2}, 3.31 \pm 0.002 \mathrm{mg} /\right.$ $\mathrm{m}^{-2}$ and $0.298 \pm 0.001 \mathrm{mg} / \mathrm{m}^{-2}$ for Chl-a, Chl-b and carotenoids, respectively) was documented in phenanthrenesupplemented soil as compared to control. The increased chlorophyll values with naphthalene treatment, however, were not significantly different $(p<0.05)$ from the control. In contrast, for Brassica juncea, the negative effects of phenanthrene and naphthalene were significantly different from Trigonella foenum-graceum. The measured deleterious effects on chlorophyll content (i.e. Chl-a, Chl-b and carotenoids) of Brassica juncea in phenanthrene-contaminated soil at $5 \mathrm{mg} / \mathrm{kg}$ were $0.500 \pm 0.001,0.884 \pm 0.001$ and $0.081 \pm 0.002$, respectively. On further addition of phenanthrene and naphthalene up to $400 \mathrm{mg} / \mathrm{kg}$, the chlorophyll parameters did not differ significantly from controls. The addition of PGPR to contaminated soil had a considerable mitigating effect on phenanthrene: the chlorophyll content increased to $3.131 \pm 0.0001,5.26 \pm 0.001$ and $0.72 \pm 0.00143$ for Chl-a, Chl-b and carotenoids, respectively, with $5 \mathrm{mg} / \mathrm{kg}$ treatment of Trigonella foenumgraceum. For Brassica juncea, the chlorophyll content increased to $1.087 \pm 0.002,1.97 \pm 0.002$ and $0.208 \pm 0.0002$ for Chl-a, Chl-b and carotenoids, respectively, with 5-mg/ kg treatment. In contrast, the addition of PGPR to the phenanthrene and naphthalene treatment in soil planted with Brassica juncea showed no significant effect as compared to Trigonella foenum-graceum, as shown in Table 2.

The above results reveal that the microbial load increased with increased concentrations of phenanthrene and naphthalene. This is because microorganisms in the rhizosphere use pollutants as a carbon source for their energy; thus the microbial load was greatest with $400 \mathrm{mg} /$ $\mathrm{kg}$ for both phenanthrene and naphthalene. However, if we compare phenanthrene and naphthalene, the microbial load was lower for naphthalene, as it is more volatile in nature than phenanthrene. In addition, we found that resistance to phenanthrene and naphthalene in both plant species was associated with shoot length, chlorophyll content and biomass of the plant. Plant biomass is a key factor in the phytoremediation process. Comparing selected treatments under the various levels of pollutants in soil, the plants and the PGPR both produce an increase in shoot height and dry weight, and there is no effect on the content of chlorophyll, as analysed by three-way ANOVA and Duncan's new multiple range test $(p \leq 0.05)$. Even under poor conditions, PGPR shows a good impact on the growth of the plants. In comparing the results with previous studies, Janoušková and Vosátka [15] revealed that inoculation of carrot with arbuscular mycorrhizal fungi (AMF) caused growth inhibition resulting from toxic cadmium (Cd) compared with the non-inoculated control. Hong et al. [13] revealed that PGPR enhanced the shoot length and biomass of maize grown in soil contaminated with diesel oil. The synergistic effect of PGPR is due to the release of organic acids, siderophores and phytochelatins, which further help to reduce soil $\mathrm{pH}$. The excellent growth parameters of plants grown in PAH-contaminated soil provide an important indication that these plants have potential value for phytoremediation. The removal of PAHs is achieved by several techniques including biodegradation $[1,26]$, photo-oxidation, leaching and bioaccumulation [24]. Many recent studies have reported the effects of PAHs on plants [31]; in yellow lupine plants, $80 \%$ reduction in the upper portion of the plant and $40 \%$ reduction in root length were observed. The plant species of rye, red clover and white mustard showed that engine oil mixed with soil enhanced the toxic effects of xenobiotics [23]. This occurs because xenobiotics in soil disturb essential nutrient uptake, which results in stunted plant growth [25]. In this study, phenanthrene and naphthalene were used as two pollutants and were mixed in the soil prior to growing seeds. The results revealed that phenanthrene exerted a greater deleterious effect than naphthalene on both Brassica juncea and Trigonella foenum-graceum. The degradative effects of these chemicals were dependent mainly on the molecular weight and structure of the compounds. Phenanthrene was more stable in the soil because of its three angular rings and lower desorption rate $[7,29]$ as compared to naphthalene, with its two-ring straight structure and easy solubility in aqueous phase. Both plants species showed high tolerance and resistivity towards these PAH compounds. Significant effects $(p \leq 0.05)$ were shown only with a low concentration of PAH compounds (i.e. $5 \mathrm{mg} / \mathrm{kg}$ ), because at lower PAH concentrations, the plants take up these compounds through the roots, showing the effect on the morphology and photosystem, and the remaining pollutants which were unavailable to the plants were degraded by microorganisms present in the soil. With a high concentration, however, the phenanthrene and naphthalene microbial degradation increased because of the availability of carbon sources for the microbes. Naphthalene was easily degraded by microbes 
Table 2 Effect of naphthalene (NHE) and phenanthrene (PHE) on chlorophyll content of Trigonella foenum-graceum and Brassica juncea with and without PGPR

\begin{tabular}{|c|c|c|c|c|}
\hline Treatment & Plant species & Chl-a (mg/ml) & Chl-b (mg/ml) & Carotenoid $(\mathrm{mg} / \mathrm{ml})$ \\
\hline \multirow[t]{2}{*}{ Control without PHE } & Trigonella foenum-graceum & $3.768 \pm 0.0015$ & $6.28 \pm 0.002$ & $1.23 \pm 0.001$ \\
\hline & Brassica juncea & $1.348 \pm 0.0015$ & $3.260 \pm 0.0015$ & $0.487 \pm 0.001$ \\
\hline \multirow[t]{2}{*}{ Control + PGPR + PHE } & Trigonella foenum-graceum & $5.833 \pm 0.0015$ & $9.48 \pm 0.001$ & $2.039 \pm 0.002$ \\
\hline & Brassica juncea & $2.148 \pm 0.001$ & $4.72 \pm 0.002$ & $0.622 \pm 0.0002$ \\
\hline \multirow[t]{2}{*}{$5 \mathrm{mg} / \mathrm{kg} \mathrm{PHE}$} & Trigonella foenum-graceum & $1.365 \pm 0.0020$ & $3.31 \pm 0.002$ & $0.298 \pm 0.001$ \\
\hline & Brassica juncea & $0.500 \pm 0.001$ & $0.884 \pm 0.001$ & $0.081 \pm 0.002$ \\
\hline \multirow[t]{2}{*}{$5 \mathrm{mg} / \mathrm{kg}$ PHE + PGPR } & Trigonella foenum-graceum & $3.131 \pm 0.0001$ & $5.26 \pm 0.001$ & $0.72 \pm 0.001$ \\
\hline & Brassica juncea & $1.087 \pm 0.002$ & $1.97 \pm 0.002$ & $0.208 \pm 0.0002$ \\
\hline \multirow[t]{2}{*}{$50 \mathrm{mg} / \mathrm{kg} \mathrm{PHE}$} & Trigonella foenum-graceum & $2.283 \pm 0.0001$ & $3.69 \pm 0.002$ & $0.427 \pm 0.002$ \\
\hline & Brassica juncea & $1.106 \pm 0.001$ & $1.88 \pm 0.001$ & $0.211 \pm 0.001$ \\
\hline \multirow[t]{2}{*}{$50 \mathrm{mg} / \mathrm{kg}$ PHE + PGPR } & Trigonella foenum-graceum & $4.986 \pm 0.0001$ & $8.63 \pm 0.002$ & $1.72 \pm 0.002$ \\
\hline & Brassica juncea & $2.135 \pm 0.001$ & $3.83 \pm 0.002$ & $0.523 \pm 0.001$ \\
\hline \multirow[t]{2}{*}{200 mg/kg PHE } & Trigonella foenum-graceum & $2.185 \pm 0.0002$ & $3.48 \pm 0.001$ & $0.357 \pm 0.002$ \\
\hline & Brassica juncea & $0.88 \pm 0.001$ & $1.504 \pm 0.001$ & $0.161 \pm 0.001$ \\
\hline \multirow[t]{2}{*}{200 mg/kg PHE + PGPR } & Trigonella foenum-graceum & $4.336 \pm 0.0002$ & $7.47 \pm 0.002$ & $1.45 \pm 0.001$ \\
\hline & Brassica juncea & $1.821 \pm 0.001$ & $3.27 \pm 0.001$ & $0.411 \pm 0.001$ \\
\hline \multirow[t]{2}{*}{400 mg/kg PHE } & Trigonella foenum-graceum & $2.094 \pm 0.0002$ & $3.05 \pm 0.001$ & $0.286 \pm 0.003$ \\
\hline & Brassica juncea & $0.814 \pm 0.002$ & $1.363 \pm 0.001$ & $0.145 \pm 0.002$ \\
\hline \multirow[t]{2}{*}{$400 \mathrm{mg} / \mathrm{kg}$ PHE + PGPR } & Trigonella foenum-graceum & $3.864 \pm 0.0002$ & $6.56 \pm 0.001$ & $1.25 \pm 0.001$ \\
\hline & Brassica juncea & $1.721 \pm 0.001$ & $3.09 \pm 0.001$ & $0.354 \pm 0.001$ \\
\hline \multirow[t]{2}{*}{ Control without NHE } & Trigonella foenum-graceum & $3.768 \pm 0.0015$ & $6.286 \pm 0.002$ & $1.236 \pm 0.001$ \\
\hline & Brassica juncea & $1.348 \pm 0.0015$ & $3.260 \pm 0.001$ & $0.487 \pm 0.001$ \\
\hline \multirow[t]{2}{*}{ Control + PGPR + NHE } & Trigonella foenum-graceum & $5.833 \pm 0.0015$ & $9.483 \pm 0.001$ & $2.0397 \pm 0.001$ \\
\hline & Brassica juncea & $2.481 \pm 0.001$ & $4.724 \pm 0.002$ & $0.622 \pm 0.002$ \\
\hline \multirow[t]{2}{*}{$5 \mathrm{mg} / \mathrm{kg} \mathrm{NHE}$} & Trigonella foenum-graceum & $1.994 \pm 0.0015$ & $3.402 \pm 0.001$ & $1.529 \pm 0.001$ \\
\hline & Brassica juncea & $0.923 \pm 0.0015$ & $1.647 \pm 0.001$ & $0.196 \pm 0.001$ \\
\hline \multirow[t]{2}{*}{$5 \mathrm{mg} / \mathrm{kg} \mathrm{NHE}+\mathrm{PGPR}$} & Trigonella foenum-graceum & $3.211 \pm 0.001$ & $5.382 \pm 0.001$ & $0.972 \pm 0.001$ \\
\hline & Brassica juncea & $1.087 \pm 0.002$ & $1.97 \pm 0.002$ & $0.246 \pm 0.002$ \\
\hline \multirow[t]{2}{*}{$50 \mathrm{mg} / \mathrm{kg} \mathrm{NHE}$} & Trigonella foenum-graceum & $3.285 \pm 0.002$ & $5.546 \pm 0.001$ & $2.626 \pm 0.001$ \\
\hline & Brassica juncea & $1.254 \pm 0.002$ & $2.202 \pm 0.002$ & $0.310 \pm 0.001$ \\
\hline \multirow[t]{2}{*}{$50 \mathrm{mg} / \mathrm{kg} \mathrm{NHE}+\mathrm{PGPR}$} & Trigonella foenum-graceum & $5.452 \pm 0.001$ & $9.250 \pm 0.001$ & $1.954 \pm 0.001$ \\
\hline & Brassica juncea & $2.406 \pm 0.001$ & $4.345 \pm 0.001$ & $0.599 \pm 0.002$ \\
\hline \multirow[t]{2}{*}{$200 \mathrm{mg} / \mathrm{kg} \mathrm{NHE}$} & Trigonella foenum-graceum & $3.242 \pm 0.0002$ & $5.475 \pm 0.002$ & $2.591 \pm 0.001$ \\
\hline & Brassica juncea & $1.216 \pm 0.001$ & $2.139 \pm 0.002$ & $0.310 \pm 0.001$ \\
\hline \multirow[t]{2}{*}{$200 \mathrm{mg} / \mathrm{kg} \mathrm{NHE}+\mathrm{PGPR}$} & Trigonella foenum-graceum & $5.090 \pm 0.001$ & $8.852 \pm 0.001$ & $1.843 \pm 0.001$ \\
\hline & Brassica juncea & $2.083 \pm 0.001$ & $3.780 \pm 0.001$ & $0.516 \pm 0.001$ \\
\hline \multirow[t]{2}{*}{$400 \mathrm{mg} / \mathrm{kg} \mathrm{NHE}$} & Trigonella foenum-graceum & $3.238 \pm 0.0001$ & $5.46 \pm 0.001$ & $2.586 \pm 0.002$ \\
\hline & Brassica juncea & $0.863 \pm 0.002$ & $0.993 \pm 0.001$ & $0.213 \pm 0.002$ \\
\hline \multirow{2}{*}{$400 \mathrm{mg} / \mathrm{kg} \mathrm{NHE}+\mathrm{PGPR}$} & Trigonella foenum-graceum & $4.864 \pm 0.001$ & $8.469 \pm 0.001$ & $1.767 \pm 0.001$ \\
\hline & Brassica juncea & $0.960 \pm 0.001$ & $1.753 \pm 0.001$ & $0.354 \pm 0.0010$ \\
\hline
\end{tabular}

Data for each parameter were analysed separately using three-way ANOVA followed by Duncan's new multiple range test. Values designated for chlorophyll content which we have taken (Chl-a, Chl-b and carotenoids) differ significantly $(p<0.05)$. Means and SD are shown $(n=5)$

because of its two rings and more volatile nature, as it can be easily evaporated as compared to phenanthrene, with its angular structure and lower degradability and volatility [17]. This shows that phenanthrene has more deleterious effects on plant species than naphthalene.

\section{Conclusion}

The plant species tested in this study germinated and grew in soil contaminated with PAH (phenanthrene and naphthalene). The negative impact of phenanthrene and 
naphthalene was observed in the growth parameters and chlorophyll content in both Brassica juncea and Trigonella foenum-graceum. PGPR plays an important role in mitigating stress conditions by enhancing the degradation of PAH compounds. This property can be exploited in the future to ensure food security. The plants treated with PGPR showed excellent tolerance and resistivity towards PAH compounds even at high concentrations in soil. Further, the experimental plants showed that the adverse effects of phenanthrene were greater than those of naphthalene in both plant species. The experiment proved that the benefits of phytoremediation increased exponentially at higher PAH concentrations for both plant species, which was due to the influence of $\mathrm{PAH}$ soil concentration on rates of biodegradation. Under the experimental conditions, the microbes tended to utilize the PAH compounds as nutrients. As the concentration increased, the degradation rate also increased, with optimal conditions at $400 \mathrm{mg} / \mathrm{kg}$ of phenanthrene and naphthalene. Based on the results of this study, further biodegradation studies are in progress to evaluate the extent of degradation of PAH compounds in soil by these plant species monitored using gas chromatography techniques.

Acknowledgements The authors are grateful to the Department of Environmental Science \& Engineering and Department of Bio-Nano Technology, University of Guru Jambheshwar, for providing the infrastructure facilities. We are thankful to the anonymous reviewers and editors for their valuable comments.

Funding The authors acknowledge UGC, DST/INT/UK R/P-14/2015 and SAP-DRS-II for financial assistance in the form of a fellowship and project.

\section{Compliance with ethical standards}

Conflict of interest On behalf of all the authors, the corresponding author declares that there is no conflict of interest in this research article.

\section{References}

1. Abdel-shafy HI, Al-sulaiman AM, Mansour MSM (2015) Anaerobic/aerobic treatment of greywater via UASB and MBR for unrestricted reuse. Water Sci Technol 71:630-637

2. Alkio M, Tabuchi TM, Wang XC, Colón-Carmona A (2005) Stress response to polycyclic aromatic hydrocarbons in Arabidosis include growth inhibition and hypersensitive response-like symptoms. J Exp Bot 56:2983-2994

3. Alkorta I, Garbisu C (2001) Phytoremediation of organic contaminants in soils. Bioresour Technol 79:273-276

4. Almaghrabi OA, Massoud SI, Abdelmoneim TS (2013) Influence of inoculation with plant growth promoting rhizobacteria (PGPR) on tomato plant growth and nematode reproduction under greenhouse conditions. Saudi J Biol Sci 20(1):57-61
5. Aprill W, Sims RC (1990) Evaluation of the use of prairie grasses for stimulating polycyclic aromatic hydrocarbon treatment in soil. Chemosphere 20:253-265

6. Chen J, Shiyab S, Han FX, Monts DL, Waggoner CA (2009) Bioaccumulation and physiological effects of mercury in Pteris vittata and Nephrolepis exaltata. Ecotoxicology 18:110-121

7. Chen SH, Aiken MD (1999) Salicylate stimulates the degradation of high molecular weight polycyclic aromatic hydrocarbons by Pseudomonas saccharophila P15. Environ Sci Technol 33:435-439

8. Cherian S, Oliveira MM (2005) Transgenic plants in Phytoremediation: recent advances and new possibilities. Environ Sci Technol 39:9377-9390

9. Edwards NT (1983) Polycyclic aromatic hydrocarbons (PAHs) in the terrestrial environment e a review. J Environ Qual 12(4):427-441

10. Gao YZ, Zhu LZ (2004) Plant uptake, accumulation and translocation of phenanthrene and pyrene in soils. Chemosphere 55:1169-1178

11. Gerhardt KE, Huang X-D, Glick BR, Greenberg BM (2009) Phytoremediation and rhizoremediation of organic soil contaminants: potential and challenges. Plant Sci 176:20-30

12. Gondek K, Kopeć M, Chmiel M, Spałek I (2008) Response of Zea maize and microorganisms to soil pollution with polycyclic aromatic hydrocarbons (PAHs). Pol J Environ Stud 17(6):875-880

13. Hong SH, Ryu HW, Kim J (2011) Rhizoremediation of diesel contaminated soil using the plant growth promoting rhizobacterium Gordonia sp. S2RP-17. Biodegradation 22:593-601

14. Howsam M, Jones KC (1998) Sources of PAHs in the environment. In: Neilson AH (ed) The handbook of environmental chemistry-PAHs and related compounds, vol 3. Springer, Berlin, pp 137-174

15. Janoušková $M$, Vosátka $M$ (2005) Response to cadmium of Daucus carota hairy roots dual cultures with Glomus intraradices or Gigaspora margarita. Mycorrhiza 15:217-224

16. Ke L, Wang WQ, Wong TWY, Wong YS, Tam NFY (2003) Removal of pyrene from contaminated sediments by mangrove microorganisms. Chemosphere 51:25-34

17. Korfmacher WA, Wolhry EL, Wehry G, Mamant OV, Natureh DFS (1980) Resistance to photochemical decomposition of polycyclic aromatic hydrocarbons vapor-adsorbed on coal fly ash. Environ Sci Technol 14:1094-1099

18. Kottler BD, Alexander M (2001) Relationship of properties of polycyclic aromatic hydrocarbons to sequestration in soil. Environ Pollut 113:293-298

19. Kunihiro M, Ozeki Y, Nogi Y, Hamamura N, Kanaly RA (2013) Benz[a]anthracene biotransformation and production of ring fission products by Sphingobium sp. StrainKK22. Appl Environ Microbiol 79:4410-4420

20. Li RL, Tan HD, Zhu YX, Zhang Y (2015) In situ simultaneous investigation of the transport of phenanthrene and Fluoranthene adsorbed onto the root surfaces to tissues of mangrove seedlings. Anal Methods 7:6828-6836

21. Lin Q, Shen KL, Zhao HM, Li WH (2008) Growth response of Zea maize $L$. in pyrene-copper co-contaminated soil and the fate of pollutants. J Hazard Mater 150(3):515-521

22. Maliszewska-Kordybach B, Smreczak B (2003) Habitat function of agricultural soils as affected by heavy metals and polycyclic aromatic hydrocarbons contamination. Environ Int 28:719-728

23. Malurzynski MJ, Maluezynska I (2009) Immunity of selected plant species on soil pollution of overworked engine oil. Inzynieria Ekologiczna 21:40

24. Nadarajah N, Van HJ, Pannu J, Singh A, Ward O (2002) Enhanced transformation of polycyclic aromatic hydrocarbons using a combined Fenton's reagent, microbial treatment and surfactants. Appl Microbiol Biotech 59:540-544 
25. Osuagwu AN, Okigbo AU, Ekpo IA, Chukuourah PN, Agbor RB (2013) Effect of crude oil pollution on growth parameters chlorophyll content and bulbils yield in air potato (Dioscorea bulbilfera L.). Int J Appl Sci Technol 3(4):37

26. Perara F, Wang S, Vishnevetsky J, Zhang B, Cole KJ, Tang D (2011) Polyaromatic hydrocarbons-aromatic DNA adducts in cord blood and behaviour scores of New York city children. Environ Health Perspect 119(8):1176-1181

27. Ren L, Zeiler LF, Dixon G, Greenberg BM (1996) Photoinduced effects of polycyclic aromatic hydrocarbons on Brassica napus (Canola) during germination and early seedling development. Ecotoxicol Environ Saf 33:73-80

28. Shaw LJ, Burns RGO (2003) Biodegradation of organic pollutants in the rhizosphere. Adv Appl Microbiol 53:1-60

29. Thorsen WA, Gregery CW, Dawian S (2004) Bioavailability of polyaromatic hydrocarbons in the aquatic environment. Environ Sci Technol 38:2029-2037
30. Weber R, Watson A, Forter M, Oliaei F (2011) Persistent organic pollutants and landfills - a review of past experiences and future challenges. Waste Manag Res 29:107-121

31. Wyszkowski M, Wyszkoska J, Ziolkowska A (2004) Effect of soil contamination with diesel soil on yellow lupine yield and microelement content. Plant Soil Environ 50(5):218

32. Xu SY, Chen YX, Lin Q, Wang WX, Xie SG, Shen CF (2005) Uptake and accumulation of phenanthrene and pyrene in spiked soils by ryegrass (Loliumperenne L.). J Environ Sci 17:817-822

Publisher's Note Springer Nature remains neutral with regard to jurisdictional claims in published maps and institutional affiliations. 